\section{Reflexões sobre um fazer etnográfico no pronto-socorro}

\section{Reflections on ethnography in the emergency department}

\section{Reflexiones sobre la labor etnográfica en un servicio de urgencias}

\section{Resumo}

A etnografia é o método de investigação por excelência da Antropologia. De ampla abrangência, ela permite o uso de várias técnicas na coleta de dados e incorpora na análise elementos observados e obtidos no campo. Na Saúde Coletiva, pode contribuir na compreensão do processo saúde/doença, dos valores e das atitudes de profissionais e de pacientes em diferentes contextos de cuidado. O objetivo deste artigo é apresentar e discutir o método etnográfico com base em uma pesquisa empirica sobre a atuação médica hospitalar diante dos limites da vida e da morte. A coleta de dados deu-se ao longo de nove meses de observação participante e de entrevistas junto a 43 médicos, 25 homens e 18 mulheres, de 28 a 69 anos, que assistem pacientes com risco de morte, em setores distintos de um hospital metropolitano de pronto-atendimento. $\mathrm{Na}$ fase de escrita, os diversos aspectos sociais e culturais - experienciados pelo pesquisador e obtidos junto aos interlocutores no campo - amalgamam uma descrição densa desta etnografia hospitalar.

Antropologia Cultural; Pesquisa sobre Serviços de Saúde; Serviços Médicos de Emergência
Janaina de Souza Aredes 1 Josélia Oliveira Araújo Firmo 1 Annette Leibing 2

Karla Cristina Giacomin 1,3

doi: 10.1590/0102-311X00118016

\section{Correspondência}

K. C. Giacomin

Núcleo de Estudos em Saúde Pública e Envelhecimento, Instituto René Rachou, Fundação Oswaldo Cruz. Av. Augusto de Lima 1715, Belo Horizonte, MG 31090-002, Brasil.

kcgiacomin@hotmail.com

1 Instituto René Rachou, Fundação Oswaldo Cruz, Belo Horizonte, Brasil.

2 Université de Montréal, Montréal, Canada.

3 Secretaria Municipal de Saúde de Belo Horizonte, Belo Horizonte, Brasil. 


\section{Introdução}

A intercessão entre as Ciências Sociais com a Saúde Coletiva/Pública é profícua e desejável ${ }^{1}$. Na abordagem dos fenômenos de interesse da saúde, a pesquisa qualitativa explora os aspectos que sustentam as relações, os motivos, os valores e as atitudes dos sujeitos, que participam da gênese das enfermidades, das maneiras como lidam com elas 1,2, bem como do seu cuidado. Assume-se cuidado ${ }^{3}$ como um modo de compreender o comportamento humano que deve ser analisado de forma relacional às experiências dos sujeitos. Trata-se de uma atenção à saúde voltada para o significado da experiência do adoecimento - físico ou mental -, que também vincula-se às práticas de promoção, proteção e recuperação da saúde 3 .

Dentre os métodos qualitativos, a etnografia sobressai por sua abrangência, diversidade de formatos (autoetnografia, metaetnografia, minietnografia, etnografia em multissítios, entre outros) e uso de variadas técnicas (entrevistas, observação participante, meios documentais e visuais, dentre outros) na coleta dos dados empíricos. E, na etapa de análise, pode incorporar novos elementos observados e ou obtidos no campo 4 .

No início do século XX, a Antropologia transferiu o seu foco tradicional da análise cultural de sociedades exóticas para a compreensão da cultura de pertença do pesquisador. Essa apropriação do método etnográfico por uma multiplicidade de objetos e populações de estudo, cada vez mais próximas do investigador, torna ainda mais complexa a tarefa de compreender a diversidade humana como culturas independentes e delimitadas 5 .

Em sociedades imersas em um mundo ambíguo e multivocal, o "fazer etnográfico" observa in loco o contexto para tentar compreender seus significados - manifestos e latentes - expressos em falas, silêncios, gestos e ações dos múltiplos atores sociais que o constituem ${ }^{6}$. Assume-se como contexto um ambiente de significado, no interior do qual elementos simbólicos se relacionam entre si, e integram uma parte da experiência vivida, uma parte construída e outra que é formada pelo ato de relacioná-las 7 .

Assim, a utilização do método etnográfico no contexto da saúde pressupõe lidar com questões metodológicas centrais que incluem a definição de limites éticos, a reflexão sobre o objeto e os próprios instrumentos de investigação aplicados 4 . Ao voltar do trabalho de campo, procura-se transmitir no texto todos os interstícios experienciados, sobretudo as fissuras do contato entre pesquisador e interlocutor. Porém, caso não haja respeito aos pressupostos etnográficos e/ou uma revisão bibliográfica apurada, dada a potencialidade e amplitude do método, corre-se o risco de sua incorporação inadequada, abrupta e inconsistente.

Obviamente não se trata aqui da primeira reflexão sobre este método para a pesquisa na saúde 4,8,9,10. Lambert \& McKevitt 9 (p. 212) sugerem que nos dados etnográficos em profundidade: "insights derivam de examinar a natureza e os significados de categorias aparentemente familiares - por exemplo, terminologias clínicas, ou construtos de serviços de saúde, tais como a 'satisfação do paciente' -, bem como de investigar como e por que tais categorias são construídas e sustentadas". Tudo isso sem desmerecer os limites éticos para não expor demais o outro nem o próprio pesquisador.

No âmbito da Saúde Coletiva, raras são as etnografias internacionais 11,12 e nacionais 8,13,14 sobre um contexto muito relevante: o da urgência e emergência. Este artigo busca apresentar e discutir o método etnográfico com base em uma investigação empírica realizada em um pronto-atendimento metropolitano. A apresentação dos processos da pesquisa, seu contexto, suas inflexões 4,15,16 e da construção do texto orientado para as etapas, especificidades e pressupostos de uma etnografia, bem como a reflexão acerca de sua densidade teórica, ilustram algumas das potencialidades e dos limites do método.

\section{Metodologia}

Trata-se de uma etnografia hospitalar sobre a atuação médica diante dos limites da vida e da morte, e como se reflete na prestação de cuidados. 


\section{Área e população de estudo}

O território escolhido é o maior pronto-socorro de uma metrópole brasileira, de reconhecida excelência em traumas e agravos clínicos dos mais complexos, no Brasil e na América Latina. Situado no hipercentro de Belo Horizonte (Minas Gerais) e habilitado como referência em alta complexidade traumato-ortopédica, configura-se como instituição de ensino, pesquisa e formação de médicos 17 .

A instituição dispõe de 440 leitos e demais dependências, onde cerca de 600 médicos e 52 residentes trabalham para atender a um intenso fluxo de pacientes, em dois blocos: um horizontal, com todas as salas de emergência, e outro vertical com as enfermarias de internação. A triagem é o ponto de partida para o atendimento emergencial e consiste na breve avaliação do estado de saúde do paciente conforme o risco à vida que a doença ou o trauma oferece 18 .

A população de estudo foi constituída por 43 médicos plantonistas de diferentes especialidades, sendo 25 homens e 18 mulheres, entre 28 e 69 anos, que assistem pacientes com risco de morte, em setores distintos do hospital.

\section{Coleta e análise dos dados}

Os dados foram coletados entre dezembro de 2012 e agosto de 2013. Além da observação participante foram realizadas e gravadas entrevistas guiadas por roteiro semiestruturado no próprio hospital.

Os participantes foram selecionados baseando-se no método conhecido como "bola de neve", em que um entrevistado sugere outro, por julgar que este tenha depoimentos relevantes para a pesquisa 19. O número final de entrevistas foi regulado pelo critério de saturação 20.

Para a análise dos dados optou-se pela antropologia interpretativa 6 que permite revelar os processos pelos quais objetos culturais são construídos e reconhecidos como significativos.

\section{Aspectos éticos}

A pesquisa está em acordo com a Resolução no 466/2012 do Conselho Nacional de Saúde. Aprovada pelos comitês de ética da Universidade Federal de Minas Gerais (CAAE: 03751612.0.0000.5149) e da Fundação Hospitalar de Minas Gerais (CEP/ADC/FHEMIG: 022/2012 - SIPRO: 29128/2012-7).

\section{Resultados e discussão}

Didaticamente, esta experiência etnográfica será apresentada em momentos não necessariamente coetâneos: "o estar lá" (o contato, a imersão no campo) e "o estar aqui" (a elaboração de um texto científico que traduz a aplicabilidade da pesquisa com base no trabalho empírico) que compõem a descrição densa 6,21 (Figura 1).

\section{O "estar lá": a mobilização dos sentidos para o olhar e a escuta atenta}

Nesta etnografia, o "estar lá" aconteceu durante nove meses, entre plantões noturnos e diurnos. Contudo, a qualidade do trabalho não depende da duração cronológica do trabalho de campo, e sim da habilidade do autor para demonstrar - de forma sistemática, plausível e convincente - em seu material empírico o ato de ter penetrado e ter sido penetrado pela cultura do outro 6 .

Assim, o ingresso no campo de pesquisa é um momento envolto de significados sutis, cabendo ao pesquisador ter cuidado e empatia 4 . Nessa etapa, acontece o contato entre investigador e interlocutor mediado pelo "pacto etnográfico", em respeito aos limites que o pesquisado impõe - por exemplo, não querer falar sobre determinado assunto - sem, contudo, deixar de observar fatos relevantes ao objeto do estudo. O mapeamento de espaços físicos, a observação, a utilização de entrevistas e/ou de outros instrumentos de mediação, compõem dados sobre elementos que à força da repetição são tomados como algo "normal e típico" para os nativos 22 . Também são perscrutados os conflitos, emoções e barreiras éticas, limitantes da "autoridade etnográfica" 23. 
Figura 1

Etapas do "fazer etnográfico".

\begin{tabular}{|c|c|}
\hline “ESTAR LÁ" & "ESTAR AQUI” \\
\hline $\begin{array}{c}\text { Estabelecimento do “pacto etnográfico" ponderando os } \\
\text { limites ditados pelo interlocutor }\end{array}$ & Cumprimento ético do "pacto etnográfico" na escrita \\
\hline Imersão do pesquisador & Distanciamento do pesquisador \\
\hline Identificação de terminologias específicas ao grupo & Interpretação minuciosa do fluxo do sistema cultural \\
\hline Observação atenta do fenômeno investigado & $\begin{array}{c}\text { Organização dos dados ordinários e identificação dos } \\
\text { "imponderáveis da vida real" }\end{array}$ \\
\hline $\begin{array}{c}\text { Utilização de técnicas de coleta de dados: observação, } \\
\text { entrevistas, mapeamentos físicos - sistematizadas no } \\
\text { diário de campo }\end{array}$ & $\begin{array}{c}\text { Análise sobre o dito e o observado traduzida em uma } \\
\text { escrita acadêmica }\end{array}$ \\
\hline
\end{tabular}

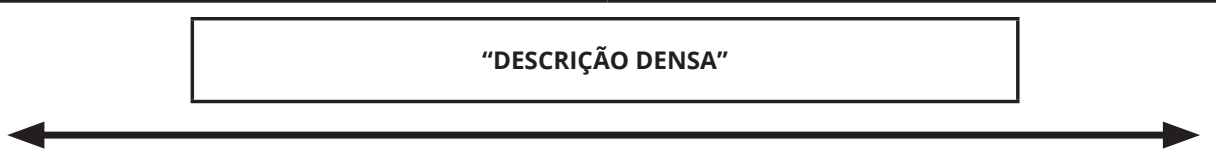

“ENCONTROS E DESENCONTROS"

Fonte: elaboração das autoras, inspirado nos estudos de Malinowski 22, Geertz 6,21 e Clifford 5.

Encontros e desencontros estão presentes ao longo da experiência de campo - aqui ancorada a Clifford 5, que a conceitua como um termo ambíguo: ora como uma presença participativa, mediada por uma relação de sensibilidade junto ao grupo ou indivíduo estudado; ora como um conhecimento que se acumula e se aprofunda.

\section{- O contato entre dois mundos: explorando o território de investigação}

Nesta experiência, até a aprovação do projeto em todas as instâncias do hospital foram consumidos sete meses. Na percepção dos médicos, o cumprimento rigoroso dos procedimentos favoreceu a atuação etnográfica e conferiu credibilidade ao trabalho.

Em uma etnografia, o território de investigação contempla um espaço físico delimitado, típico e próprio; vestuário e papéis específicos para cada grupo e/ou setor, segundo as suas funções; grau de pertencimento e hierarquias; rituais de procedimentos; linguagem; entre outros atributos 22 .

O mapeamento do território possibilitou delimitar os espaços de interesse - locais que os médicos assistem pacientes graves com risco de morte, e conhecer alguns dos protocolos utilizados na instituição para o paciente grave. Nessa etapa também aconteceu a exploração da estrutura física e organizacional da instituição.

No hospital, a chegada de uma antropóloga gerou curiosidade. O primeiro médico que lhe foi apresentado interpelou-a: "Você vai passar um tempo 'internada' aqui com a gente? É um tema difícil, você está preparada? Bem mórbido, não? Mas, ao mesmo tempo, muito interessante... O que te levou a escolher esse tema tão excêntrico? Você está querendo matar alguém? [risos]”. Com essas palavras desconcertantes de acolhida, o profissional externou sua dificuldade em entender por que alguém se interessava em compreender a morte.

Muitos médicos diziam: "Que legal! Nunca conheci uma antropóloga. Me conte um pouco sobre a profissão”. A maioria ligava a Antropologia a grupos indígenas, sociedades tradicionais, pois etnografias urbanas ainda surpreendem e expõem a complexidade e a heterogeneidade dos grandes centros contemporâneos que introduzem novas dimensões na experiência e comportamento humanos 24 . 
Alguns médicos brincavam: "Sai pra lá... Você quer matar meu paciente... [risos]". Um residente em especial sempre perguntava em tom jocoso: "Muitas mortes hoje? [risos]". Outro profissional alertava: "Você vai ver muito o que está querendo, está no lugar certo...", "Coitadinha... será que você vai dar conta desse cenário?”. No campo, a pesquisadora recebeu vários apelidos. Um profissional, encantado pela excentricidade da Antropologia, pesquisou e começou a chamá-la de "Papua Nova Guiné" - remetendo a Malinowski, expoente desta ciência. "Dra. Morte", "Dama da Morte", "Papa Defunto", inicialmente interpretados como tentativas de quebrar a cerimônia, talvez fossem uma maneira velada de demonstrar os incômodos do serviço frente à temática investigada. Assim, para reduzir o estranhamento das equipes, a pesquisadora apropriou-se do comportamento dos observados e também passou a utilizar de um eufemismo para se referir ao seu tema de interesse: "paciente grave com risco de morte".

Durante a observação, ficou evidente a intensidade do ritmo de atuação de todos que trabalham no pronto-atendimento. No diário de campo, há o registro do Protocolo "Onda Vermelha" (encaminhamento imediato do paciente com risco iminente de morte ao bloco cirúrgico):

"Ouve-se uma sirene vinda do corredor da emergência. Médicos e enfermeiros saem da Sala de Reanimação às pressas empurrando uma maca pelo corredor com destino ao bloco cirúrgico que já está com as portas abertas para receber o paciente. É um cenário de muita adrenalina não só para quem vê como para os profissionais ali envolvidos. É um corre-corre em prol da vida (...). Tudo é realizado muito rápido e de forma intensa, uma orquestração de manobras, em que cada profissional sabe exatamente o que fazer" (Diário de Campo, 2013).

No primeiro plantão noturno, dois enfermeiros empurravam rapidamente uma maca em direção à sala de reanimação falando à equipe: "É PAF, É PAF!!". Completamente perdida, a última coisa que ocorreu à pesquisadora foi que "PAF" era como se referiam a um ferimento provocado por arma de fogo.

Assim, outro desafio foi compreender a linguagem dos profissionais de saúde, composta por códigos e significados específicos à dinâmica hospitalar. Foi necessário realizar uma análise da conversação - estruturas e propriedades formais da linguagem, mediada por padrões 25 restritos a um grupo específico que, entre si, não precisam ser explicados. Essa linguagem, longe de ser simplesmente um jargão, ao mesmo tempo abrevia, especifica e define os termos, reduzindo as margens para o desentendimento (Tabela 1).

Era frequente, durante os plantões, ouvir frases como: "Ele está chocado"; "Ela sofreu duas PCRs e um TCE"; "Ele parou! Punciona noradrenalina!"; "Isso é 'crise conversiva', ela não está passando mal", dentre outros padrões.

Ao contrário de outros contextos etnográficos, nos quais o pesquisador se posiciona apenas como observador; em uma etnografia urbana 24 , ele permanece diluído entre seus interlocutores de pesquisa. Usar jaleco branco de manga comprida, calçado fechado e crachá de identificação funciona como um dispositivo para entrar e circular no hospital. Quando transitava sem essa indumentária, a antropóloga era vista como uma pessoa estranha: "Está procurando alguém?", "É parente de algum paciente?", "Aqui não pode ficar acompanhante". À semelhança da experiência narrada por Chazan 26, o jaleco representava um símbolo tão potente de pertencimento ao grupo dos médicos que, por vezes, a pesquisadora chegou a ser confundida com um deles: "Bom dia, Dra.!", "Parece que o plantão será tranquilo".

Confusão também favorecida por se tratar de pessoa branca, com idade próxima à de alunos em formação acadêmica, sempre inserida no grupo de médicos, e que, em certos momentos, participava empurrando macas, chamando funcionários, apanhando objetos, discutindo casos clínicos. Da mesma forma, Mol 27 foi bem aceita pelas equipes dos hospitais que investigava. Para Bonet 28, o trabalho de campo torna-se um misto de "participação observante e observação participante", pois durante a coleta de dados antropólogos entram e saem de cena para observar tudo, apreender e aprender sobre o seu objeto de estudo.

Essa imersão oportunizou acessar a prática profissional dos médicos e sua relação com os limites vida x morte. Tenta-se fazer uma etnografia do "encontro" entre a cultura etnografada e a cultura do etnógrafo 15: durante o "fazer etnográfico" o antropólogo entra noutra cultura, sem deixar de pertencer à sua, tornando-se assim um indivíduo duplamente marginal que vive simultaneamente em dois mundos mentais distintos 29 . Na interlocução entre os universos ético e êmico, um observador de fora (outsider) utiliza os instrumentos éticos da própria cultura para ver o outro eticamente, sem, contudo, se tornar um deles. 
Tabela 1

Síntese dos padrões utilizados no pronto-socorro.

\begin{tabular}{|c|c|}
\hline Padrões & Significado \\
\hline Autoextermínio & Suicídio \\
\hline Chocado & $\begin{array}{l}\text { Condição hemodinâmica em que há uma má perfusão tecidual, de forma que o oxigênio } \\
\text { não consegue atingir os tecidos }\end{array}$ \\
\hline Crise conversiva & $\begin{array}{c}\text { Refere-se ao quadro do paciente com interesse secundário na consulta ao médico, tais como: pedir atestado, } \\
\text { chamar a atenção de alguém, dentre outros. Ele se contrapõe ao termo neurológico "crise convulsiva”, } \\
\text { quando a pessoa tem uma crise epiléptica verdadeira }\end{array}$ \\
\hline LET & Limitação de esforço terapêutico \\
\hline PAF & Perfuração por arma de fogo \\
\hline $\mathrm{PAB}$ & Perfuração por arma branca \\
\hline PCR & Parada cardiorrespiratória \\
\hline Paciente parado & Aquele paciente que sofreu parada respiratória e cardiorrespiratória (e vice-versa) \\
\hline Prognóstico reservado & Casos em que não há mais o que fazer para reverter o quadro clínico \\
\hline Prognóstico sombrio & Casos em que não há mais o que fazer para reverter o quadro clínico \\
\hline Rebaixado & Paciente com o nível de consciência baixo \\
\hline Reflexo de Lázaro & Reflexo medular em pacientes com morte encefálica \\
\hline Ressuscitação & Reanimação cardíaca para o paciente em parada cardiorrespiratória \\
\hline TCE & Traumatismo crânio-encefálico \\
\hline
\end{tabular}

Quanto às entrevistas, pretendia-se realizá-las no horário de almoço ou em outro período de descanso dos médicos, mas o ritmo incessante de trabalho dos pesquisados e a dinâmica dos setores não o permitiram. Pela menor possibilidade de interrupção foram realizadas em salas de descanso dos médicos ou, excepcionalmente, quando a demanda era intensa, na própria sala de emergência. Como o tempo livre era escasso, a princípio os médicos ficavam ansiosos quanto à duração da entrevista, mas a maioria excedeu o limite previsto de 25 a 30 minutos e algumas ultrapassaram uma hora.

Alguns médicos ofereceram mais resistência do que outros e indagavam: "Vai demorar muito? Tenho que evoluir um paciente e fazer uma internação”. Contudo, durante a gravação, empolgavam-se, falavam muito e alertados sobre o tempo respondiam: "vamos continuar, ainda dá tempo para terminar o meu trabalho, fique tranquila".

Contrapondo-se ao desconforto inicial, os interlocutores descobriam grande interesse em participar: "Finalmente alguém preocupado com nós médicos! Quase ninguém dá atenção para gente... muito menos fazem pesquisa sobre a nossa categoria...". Uma entrevistada reconheceu: "Que alivio falar sobre isso... a gente nunca fala dessas coisas que vivenciamos aqui, mas que, talvez, não falamos pela falta de preparo. Me ajudou compartilhar minhas experiências". Entrevistas fazem o interlocutor pensar sobre questões do cotidiano acerca das quais não costuma refletir, e como numa catarse se sente afetado pelos assuntos abordados. Trata-se de uma autoanálise ${ }^{30}$, uma fala que expressa reflexões sobre assuntos até então reprimidos e reservados.

Independentemente da acolhida, curiosidade e interesse quanto ao tema, os investigados não entendiam como seria possível alguém "captar” tais informações "apenas” observando. Eles ignoravam o quanto observar pode ser transformador para os envolvidos - pesquisador e interlocutores.

\section{- Os "imponderáveis da vida real" e as diferenças entre o pensar e o agir}

Nesta etnografia, uma gama enorme de dados foi coletada e ajudou a compreender como o conhecimento médico num pronto-socorro é consolidada na prática. Para Malinowski 22 (p. 33): "se, a par daquilo que é o normal e típico, o Etnógrafo anotar cuidadosamente os pequenos e grandes desvios à norma, ele estará a balizar os dois extremos entre os quais se movimenta a normalidade". Esses "imponderáveis da vida 
real" 22 devem ser criteriosamente analisados, pois embora inerentes ao objeto de estudo, não estão localizados em sua estrutura, e somente uma observação exaustiva permite identificá-los.

No momento da coleta de dados desconhecia-se a utilidade de várias informações, uma vez que o antropólogo acaba reunindo materiais aparentemente descoordenados devido ao imaturo conhecimento sobre as conexões que podem ser feitas baseando-se nos elementos descritos 23 . Depois de distanciados do campo, sua relevância para compreender certas nuances que medeiam a atuação médica naquele contexto ficou evidente.

Dentre os muitos episódios vivenciados em campo, um problema transversal e não específico da área da saúde, no entanto, a afeta: a violência 8,31. E, subtendido a ela, tudo aquilo que revela. Por exemplo, insatisfeito com a demora no atendimento de seu familiar, um homem ateou fogo em uniformes dos médicos no banheiro e fugiu em seguida; ou um furto no armário da equipe de enfermagem praticado por um paciente usuário de droga que havia recebido alta. Além disso, ameaças contra os profissionais de saúde também são frequentes naquele contexto, mas pouco valorizadas. Na sala de recuperação, um homem recém-operado de diversas perfurações por arma de fogo falou à médica: "Se você não me der água agora, quando eu sair daqui você vai ter problema...". Ela argumentou: "Se eu te der água você vai morrer, você quer isso?". Ele ficou quieto e calou-se. Segundo essa profissional, apesar das ameaças: "Quando saem daqui eles agradecem bastante. Mas que eles intimidam e dão medo... isso é verdade. Você viu o tamanhão dele?! [risos]”.

Logo, nessa etnografia também emergiu o quanto a violência presente no cotidiano dos trabalhadores das emergências fundamenta definições e julgamentos próprios destes profissionais acerca do que seja a violência, nas esferas pública e privada 8 . É válido ressaltar que esse hospital é conhecido como "pronto-socorro policial", com dois policiais de plantão em tempo integral, direcionados à investigação de acidentes de trânsito, de tentativas de homicídio e a fazer contato com o Instituto Médico Legal para a necropsia e a identificação das vítimas.

Assim, a realidade de um pronto-socorro não pode ser tomada como um dado a priori, os atores envolvidos interferem - e sofrem interferência - de eventos que ocorrem na práxis do serviço. Para $\mathrm{Mol} 27$, as técnicas dos profissionais não se restringem ao conhecimento acadêmico: fundem-se nos fatos que ocorrem no ambiente hospitalar e, sobretudo, no que é vivido pelos médicos no cotidiano do serviço. Isso se dá por conexões que podem se coordenar, se chocar ou se sobrepor na dinâmica do grupo estudado 27.

Contudo, nota-se um hiato entre o conhecimento tácito - expresso nas entrevistas - e a aceitação das normas sociais e o grau pelo qual, na prática - observado no campo -, os médicos se submetem a elas. Por exemplo, durante uma reanimação cardiopulmonar, enquanto um profissional parou a manobra ao término do tempo protocolar, o outro desobedeceu ao protocolo e insistiu obstinadamente na tentativa de recuperação da paciente. Caso nos ativéssemos somente ao campo ou exclusivamente às entrevistas, tais contradições não se revelariam.

Portanto, a abordagem etnográfica da prática médica é construída na tensão entre empiria e teoria. Compreendendo que tal diferença existente entre "o que dizem e o que fazem" reflete também a estrutura institucional biomédica a que pertencem, na qual a luta pela vida (e cura) se sobrepõe a uma realidade de morte (e impossibilidade curativa) bastante presente.

\section{- O "afetar" e o "estar afetado": um risco inerente ao percurso etnográfico}

$\mathrm{Na}$ Antropologia, a experiência pessoal é um meio de conhecimento ${ }^{7}$. Na escrita desta etnografia buscou-se retratar ao máximo as sensações vivenciadas, tendo como suporte os órgãos sensoriais 15 para permitir a aproximação intensa da lógica do grupo estudado.

Trata-se de seres humanos lidando com outros seres humanos. Um pronto-atendimento é a face mais reveladora da sociedade e de todas as suas mazelas. Viam-se pessoas ensanguentadas, profissionais lutando contra o tempo para realizarem os cuidados demandados, semblantes tristes, alegres, tensos, em suma, uma azáfama de movimentos, sons, esperanças e decepções simultâneas. Sentia-se uma mescla de odores de materiais de limpeza, secreções, medicamentos. Ouviam-se os ruídos de uma "orquestra desafinada" feita de sinais sonoros de aparelhos, gemidos e suspiros dos pacientes, conversas e ordens dos profissionais, choros e reclamações de familiares e acompanhantes. A maior 
dificuldade foi estar ao lado do "grande queimado", pelo impacto visual e odor carregado, difíceis de serem traduzidos em palavras.

No campo, houve momentos dramáticos em que a pesquisadora duvidou de sua capacidade de permanecer naquele local. Uma médica confortou-a: "Pelo menos você tem essa opção... eu tenho que secar as lágrimas e voltar fazendo cara de paisagem". E outra previu: "Nós médicos temos o nosso 'armário de mortos e de histórias... você também vai sair daqui com o seu” e, de fato, o armário construído ao longo da etnografia encontra-se repleto de mortes e de histórias.

Naquele ambiente de trabalho sério e intenso, o receio de que a presença de alguém não ligado à área da saúde atrapalhasse a rotina da instituição não se confirmou. Todos os membros das equipes foram acolhedores e cuidadosos para com a antropóloga. Como a pesquisadora tem a pele um tanto quanto alva, quase pálida, os médicos sempre queriam colocar soro com glicose: "Acho que deve fazer alguns exames, quer que eu faça o pedido?”. A noção de cuidado esteve sempre presente em campo e os pesquisados estavam o tempo todo ligados no exercício da medicina, no alívio de dores, traumas e doenças. Ao recusar remédio para uma crise de dor de cabeça, um neurocirurgião a interpelou: "O quêe! Você está sentindo dor e não vai tomar remédio?!".

Estudos 15,28 evidenciam a relevância da relação de amizade entre o pesquisador e seus interlocutores para o desenvolvimento da pesquisa. No campo, essa cumplicidade estendeu-se para a ligação com outros atores envolvidos na dinâmica hospitalar. Por exemplo, ao término da internação de um senhor septuagenário, hospitalizado durante três meses por tentativa de suicídio, seu acompanhante presenteou a antropóloga com sabonetes artesanais de sua fabricação. Essas parcerias e amizades podem afetar outras esferas da vida, para além da consolidação formal de uma pesquisa.

Surpreendidos pelo tema, muitos médicos se emocionaram, principalmente quando remetia a mortes que os marcaram na trajetória profissional. Demonstrações que também surpreenderam a pesquisadora: "ao se render às preocupações dos outros, o(a) pesquisador(a) de campo entra em relação com pessoas para as quais não há imaginação ou especulação suficientes que sirvam de preparação prévia” 23 (p. 351).

Depois de algum tempo em campo, é inevitável o envolvimento com as atividades e sensações dos "nativos" em relação ao foco de estudo: a morte e, por conseguinte, a vida. Tristeza e pavor foram sentidos quando o médico notificava a família da morte ou da impossibilidade de recuperação; intensa alegria quando o paciente se recuperava e os esforços se viam recompensados; ou ainda, instantes de grande aflição, quando era preciso tomar decisões difíceis na conclusão de diagnósticos e definição de condutas. Momentos de dificuldades, inerentes a um trabalho de campo, referiam-se ao plano do não dito: as emoções subjacentes à vida e à morte 10. Rezende \& Coelho 32 (p. 74) questionam se as emoções teriam um caráter individual ou social, uma vez que as "experiências emocionais são, a um só tempo, subjetivas e sociais".

Em outras situações, o pesquisador mais participava do que observava, da mesma forma a sua presença também afetava os interlocutores 16 . Mesmo deixando-se afetar por toda a dinâmica e emoções do contexto, a descrição foi feita com base no mundo próprio do pesquisador. Nesse exercício, foi possível perceber que o ato de compreender o outro é uma forma de autocompreensão. As angústias vivenciadas pelos médicos se estendem ao observador. A cada dia de pesquisa, reelaborações e autoquestionamentos sobre tais percepções eram efetuados, próximos à experiência de Crapanzano 33 que se envolveu na narrativa do seu interlocutor a ponto de fazer um exercício de pensamento sobre si mesmo.

Esse afetar 16, mediado pela alteridade, baliza a consolidação da etnografia. É interessante pontuar que ao longo das entrevistas era necessário alternar de posição e assumir o lugar do entrevistado para tentar compreender o que ele queria dizer. Para Bourdieu 30, no ato da entrevista, o pesquisador sofre uma conversão do olhar, uma vez que faz como seus os problemas enfrentados pelo outro, a fim de compreendê-los da forma como se apresentam.

Cabe aqui destacar a influência do temperamento do etnógrafo no desenvolvimento do trabalho 10. Em campo, a pesquisadora percebeu que sua personalidade e certa habilidade emocional para lidar com o território e o contexto estudados viabilizaram a continuidade do trabalho. 


\section{O "estar aqui": a tradução da experiência alteritária para o texto}

O desenvolvimento de uma etnografia está do começo ao fim imerso na escrita 5 , que não se resume à soma das anotações no diário de campo com a transcrição de entrevistas. No "estar aqui" trata-se de uma escrita sobre o "encontro ou choque" entre mundos distintos 15 , mediado por afetos 16 do pesquisador: uma relação de sentido 34 entre o discurso de quem observa e quem é observado.

Quando a autoridade etnográfica fala sobre "o outro" faz-se imprescindível realizar a conjunção dos dados empíricos com a teoria - exercício no qual se realiza a comunicação entre o conhecimento objetivo e a reflexão subjetiva do pesquisador. Assim, com a escrita, ou seja, a interpretação do que foi observado no trabalho de campo, adentra-se ao estágio final da pesquisa que, em suma, consiste no "olhar, ouvir, escrever", proposto por Cardoso de Oliveira 35. Intercalado a isso, Latour 36 ressalta a legitimidade do texto antropológico, que não seria "nem superior nem inferior" às descrições dos próprios cientistas. A única diferença é que eles teriam um laboratório e os antropólogos, um texto.

Essa etapa abrange um processo complexo devido ao confronto de múltiplas subjetividades e constrangimentos políticos que fogem ao controle do pesquisador ${ }^{4}$, envolvendo o seu "distanciamento" e respeito ao "pacto etnográfico" firmado com os interlocutores. Na etnografia hospitalar cabe, sobretudo, descrever e analisar a saúde, a doença e/ou cuidado inserido em uma complexidade de relações socioculturais, políticas, econômicas e cosmológicas que compõem uma ordem social 1.

A Antropologia é uma ciência que permite observar a maneira como o outro nos compreende por meio dos seus próprios termos e vice-versa. Nessa experiência relacional e dialética "inventa-se" a cultura do outro 7 envolvendo valores, concepções e sensibilidades do próprio antropólogo. Para McLean \& Leibing 10, aceitar que outras vozes e fontes de significação participem da construção do conhecimento, inclusive as emoções do próprio pesquisador, possibilita que elementos que permaneceriam nas sombras do trabalho de campo sejam revelados.

Assim, o texto etnográfico revela a interpretação de dois mundos, o que torna o método desafiador ao contemplar uma escrita que também envolve uma imaginação decorrente dos efeitos da própria pesquisa de campo 23.

Além disso, colocar ou não todas as fissuras envolvidas na pesquisa (conflitos vivenciados em campo, emoções experimentadas, por exemplo) reflete a cautela do pesquisador para que a escrita não se limite ao seu ponto de vista. A utilização de um "filtro ético" na decisão de expor ou não situações comprometedoras sobre as quais os interlocutores não teriam ciência do seu uso, reforça a noção de que a etnografia é sempre limítrofe.

Indubitavelmente, a escrita etnográfica traz implícitos (ou explícitos) dilemas inerentes ao percurso do trabalho de campo, sendo necessário cautela para retratá-los, afinal, os interlocutores são mais do que entrevistados que respondem a perguntas: são informantes de fato e têm total controle sobre a informação disponibilizada 23 . Os sujeitos da pesquisa etnográfica podem questionar o que foi escrito sobre eles, o que envolve a autoria, mas também representa uma forma de contestar demandas e um meio de dominar as diversas situações de campo ${ }^{37}$. Nesse sentido, por temer a exposição desnecessária e indesejada dos envolvidos, determinadas ações e discursos dos interlocutores foram arbitrariamente ocultados no redigir desta etnografia.

Conforme Clifford 5, a observação participante, se traduzida de forma estrita, é uma "fórmula paradoxal e enganosa". Em certa medida falar sobre um outro mundo com base no seu próprio mundo permite a dialética entre experiência e interpretação na qual se constrói o texto. Cada etnografia implica uma escolha estratégica entre os vários modos de autoridade etnográfica, tais como o experiencial, o interpretativo, o dialógico e o polifônico, presentes nos textos. Cabe ao pesquisador propor ou se apropriar de um ou mais paradigmas conforme o seu objeto de estudo 5 .

No encontro etnográfico todos saem afetados pela construção de uma teoria do outro, por meio do acesso a seus costumes, práticas, hábitos, baseando-se em dados empíricos que não se vinculam apenas à entrevista nem à observação, mas a um modelo resultante da imbricação de todos estes elementos. Isso significa sumariamente: tirar grandes conclusões com base em fatos pequenos, mas densamente entrelaçados; apoiar amplas afirmativas sobre o papel da cultura na construção da vida coletiva empenhando-as exatamente em especificações complexas ${ }^{6}$. 


\section{Contribuições de uma "descrição densa" para a compreensão da vida e da morte no cuidado médico}

Diferentemente do que marcou a Antropologia - estudar tribos indígenas, relações de parentesco, bruxaria -, nas ditas sociedades modernas busca-se compreender as grandes instituições 36. Abordar a prática hospitalar de uma categoria profissional que tem como um de seus pressupostos a luta contra a morte é ainda mais delicado e, ao mesmo tempo, fascinante. Mas foram esses extremos e limites que despertaram o interesse desta pesquisa.

Por sua vez, no grupo de antropólogos a reação, seja em sala de aula ou em outro evento, também era desconcertante: "Você vai entrevistar médicos!?... Eles não vão te responder nada..." "O ego dos médicos é muito superior ao dos outros mortais, eles se consideram deuses". Claro que incomodou ouvir as pessoas depreciando os futuros interlocutores.

Em campo, essa impressão dos colegas de que os médicos seriam sempre frios e superiores diante do sofrimento de outrem foi-se desfazendo à proporção que encontrava médicos compassivos e afetivos na sua práxis, sempre dispostos a ajudar a pesquisadora na imersão em locais restritos num hospital, e nas entrevistas com riqueza de detalhes e muita sinceridade, decorrentes também do interesse deles pelo tema. Contudo, para corresponder à expectativa social, precisavam fazer uso de uma espécie de "escudo ou máscara" para se protegerem e administrar essa sensibilidade em relação ao sofrimento do outro.

Mais do que salvar vidas ou encarar a morte, esse território de investigação nos permite enxergar o que tentamos desesperadamente escamotear de nossos sentidos: as mazelas e a violência da sociedade brasileira na forma da crueldade, da exclusão social, da falta de condições de trabalho na saúde pública e da morte em todo o seu espectro. A elucidação dessas questões revelou que a atuação dos médicos ultrapassa o que é propagado pelo senso comum. São pessoas dotadas de emoções e sentimentos que lidam com pessoas dotadas de emoções e sentimentos.

Essa etnografia experiencial, hospitalar e urbana discorre sobre dores, odores, sensações, emoções de profissionais, pacientes e do próprio pesquisador diante da vida e da morte. Por meio de uma "descrição densa" 6 revelam-se as tensões entre os conceitos estabelecidos pelo senso comum e a teoria que o pesquisador leva a campo, o que oferece novos dados e suscita questões para outros estudos.

\section{Considerações finais}

O método etnográfico revela contextos socioculturais específicos que podem ajudar a compreender a dinâmica do cuidado em várias práticas de intervenções na saúde. Apesar da sua riqueza e talvez por sua especificidade, ele ainda precisa ser mais discutido, especialmente em pesquisas na Saúde Coletiva.

Embora permita a utilização de várias técnicas na coleta dos dados, sua aplicação incorre em desafios e dilemas envolvendo a ética ao falar sobre o "outro"; cautela em relação aos conflitos e emoções experienciados em campo; consciência de que todo conhecimento antropológico tem uma implicação política e social, sem desconhecer os limites que essa metodologia apresenta. Nesse método, o saber teórico vai sendo construído conjuntamente à coleta dos dados, que podem ser obtidos em várias etapas da investigação, na perspectiva de uma descrição dialógica com o outro.

Uma experiência etnográfica na saúde requer um texto que fale do afetar mútuo de duas culturas, em que pesquisador e interlocutor contribuem com a matéria-prima dos sentidos e valores subjacentes ao encontro alteritário, que possibilita compreender o processo saúde/doença e aprimorar o cuidado em um dado contexto. 


\section{Colaboradores}

J. S. Aredes trabalhou na concepção do projeto, coleta, análise, interpretação dos dados e redação. J. O. A. Firmo, A. Leibing e K. C. Giacomin trabalharam na análise e interpretação dos dados, redação, revisão crítica relevante do conteúdo intelectual e aprovação final da versão a ser publicada.

\section{Referências}

1. Minayo MC. A produção de conhecimentos na interface entre as ciências sociais e humanas e a saúde coletiva. Saúde Soc 2013; 22:21-31.

2. Uchôa E, Firmo JOA, Lima-Costa MF, Corin E. An anthropologic study on strategies for addressing health problems among the elderly in Bambuí, Minas Gerais State, Brazil. Cad Saúde Pública 2011; 27 Suppl 3:S370-7.

3. Ayres JRCM. Cuidado: trabalho e interação nas práticas de saúde. Rio de Janeiro: Centro de Estudos e Pesquisa em Saúde Coletiva, Instituto de Medicina Social, Universidade do Estado do Rio de Janeiro/Abrasco; 2011.

4. Caprara A, Landim LP. Etnografia: uso, potencialidades e limites na pesquisa em saúde. Interface Comun Saúde Educ 2008; 12:363-76.

5. Clifford J. A experiência etnográfica: antropologia e literatura no século XX. Rio de Janeiro: Editora UFRJ; 1998.

6. Geertz C. A interpretação das culturas. Rio de Janeiro: LTC; 1989.

7. Wagner R. A invenção da cultura. São Paulo: Cosac Naify; 2010.

8. Deslandes SF. Frágeis deuses: profissionais da emergência entre os danos da violência e a recriação da vida. Rio de Janeiro: Editora Fiocruz; 2002.

9. Lambert H, McKevitt C. Anthropology in health research: from qualitative methods to multidisciplinarity. BMJ 2002; 325:210-2.

10. McLean A, Leibing A, editors. The shadow side of fieldwork: exploring the blurred borders between ethnography and life. New York: John Wiley \& Sons; 2008.

11. Brummell S, Seymour J, Higginbottom G. Cardiopulmonary resuscitation decisions in the emergency department: an ethnography of tacit knowledge in practice. Soc Sci Med 2016; 156:47-54.

12. Cooper S, Porter J, Endacott R. Mixed methods research: a design for emergency care research? Emerg Med J 2011; 28:682-5.

13. Seminotti E, Neves E. Dos dramas de Narciso: reflexões antropológicas a partir de uma etnografia de um Serviço de Atendimento Móvel de Urgência de João Pessoa - PB. Ilha Revista de Antropologia 2014; 16:175-202.

\section{Agradecimentos}

Ao $\mathrm{CNPq}$ (bolsa de produtividade) e à Capes (bolsa de doutorado).

14. Signorelli MC, Auad D, Pereira PP. Violência doméstica contra mulheres e a atuação profissional na atenção primária à saúde: um estudo etnográfico em Matinhos, Paraná, Brasil. Cad Saúde Pública 2013; 29:1230-40.

15. Read K. The high valley. New York: Charles Sribner's Sons; 1965.

16. Favret-Saada J. Ser afetado. Cadernos de Campo 2005; 14:155-62.

17. Ministério da Saúde. Portaria no 90, de 27 de março de 2009. Diário Oficial da União 2009; 30 mar.

18. Portal da Enfermagem. Protocolo de Manchester. http://www.portaldaenfermagem. com.br/plantao_read.asp?id=1461 (acessado em 09/Dez/2012).

19. Patton MQ. Qualitative research and evaluation methods. London: Sage Publications; 2002.

20. Fontanella BJB, Luchesi BM, Saidel MGB, Ricas J, Turato ER, Melo DG. Amostragem em pesquisas qualitativas: proposta de procedimentos para constatar saturação teórica. Cad Saúde Pública 2011; 27:389-94.

21. Geertz C. Obras e vidas: o antropólogo como autor. 2a Ed. Rio de Janeiro: Editora UFRJ; 2005.

22. Malinowski B. Argonautas do Pacífico Ocidental: um relato do empreendimento e da aventura dos nativos nos arquipélagos da Nova Guiné, Melanésia. São Paulo: Abril Cultural; 1976.

23. Strathern M. O efeito etnográfico. São Paulo: Cosac Naify; 2014.

24. Velho G. Antropologia urbana: encontro de tradições e novas perspectivas. Sociologia, Problemas e Práticas 2009; 59:11-8.

25. Coulon A. Etnometodologia. Petrópolis: Editora Vozes; 1995.

26. Chazan LK. Vestindo o jaleco: reflexões sobre a subjetividade e a posição do etnógrafo em ambiente médico. Cadernos de Campo 2005; 13:15-32.

27. Mol A. The body multiple: ontology in medical practice. London: Duke University Press; 2002. 
28. Bonet O. Saber e sentir: uma etnografia da aprendizagem da biomedicina. Rio de Janeiro: Editora Fiocruz; 2004.

29. Evans-Pritchard EE. Bruxaria, oráculos e magia entre os Azande. Rio de Janeiro: Zahar; 2005.

30. Bourdieu P. A miséria do mundo. Petrópolis: Editora Vozes; 1998.

31. Minayo MCS. A violência social sob a perspectiva da saúde pública. Cad Saúde Pública 1994; 10 Suppl 1:7-18.

32. Rezende CB, Coelho MC. Antropologia das emoções. Rio de Janeiro: Fundação Getulio Vargas; 2010. (Série Sociedade e Cultura).

\section{Abstract}

Ethnography is the principal research method in Anthropology. With a broad scope, it allows using different data collection techniques and incorporates elements observed and obtained in the field into the analysis. In Public Health, it can contribute to understanding the health/disease process and health professionals' and patients' values and attitudes in different healthcare settings. The aim of this article is to present and discuss the ethnographic method based on an empirical study of physicians' hospital work in the face of the limits between life and death. Data collection involved nine months of participant observation and interviews with 43 physicians ( 25 men and 18 women), 28 to 69 years of age, treating critical patients in different departments of a metropolitan emergency hospital. The various social and cultural aspects experienced by the researcher and obtained from the interlocutors in the field provide a dense description of this hospital ethnography.

Cultural Anthropology; Health Services Research; Emergency Medical Services
33. Crapanzano V. Tuhami - portrait of a Moroccan. Chicago: Chicago University Press; 1985.

34. Viveiros de Castro E. O nativo relativo. Mana 2002; 8:113-48.

35. Cardoso de Oliveira R. O trabalho do antropólogo. Brasília: Paralelo 15/São Paulo: Editora UNESP; 2000.

36. Latour B. A vida de laboratório: a produção dos fatos científicos. Rio de Janeiro: Editora Relume-Dumará; 1997.

37. Ramos AR. Do engajamento ao desprendimento. Campos 2007; 8:11-32.

\section{Resumen}

La etnografía es el método de investigación por excelencia de la Antropología. De amplio espectro, permite el uso de varias técnicas en la recogida de datos, e incorpora en el análisis elementos observados y obtenidos en trabajos de campo. En la Salud Colectiva puede contribuir a la comprensión del proceso salud/enfermedad, de los valores y actitudes de profesionales y de pacientes en diferentes contextos de cuidado. El objetivo de este artículo es presentar y discutir el método etnográfico, en base a una investigación empírica sobre la actuación médica hospitalaria ante los límites de la vida y la muerte. La recogida de datos se produjo a lo largo de nueve meses de observación participante y de entrevistas junto a 43 médicos, 25 hombres y 18 mujeres, de 28 a 69 años, que asisten a pacientes con riesgo de muerte, en sectores distintos de un hospital metropolitano de urgencias. En la fase de escritura, los diversos aspectos sociales y culturales -vividos por el investigador-y, obtenidos junto a los interlocutores en el trabajo de campo, condensan una descripción densa de esta etnografía hospitalaria.

Antropología Cultural; Investigación sobre Servicios de Salud; Servicios Médicos de Urgencia
Recebido em 06/Jul/2016

Versão final reapresentada em 18/Out/2016 Aprovado em 04/Nov/2016 